\title{
Pengaruh Metode Pengolahan Terhadap Aktivitas Antioksidan Dan Karakteristik Teh Herbal Daun Matoa (Pometia pinnata)
}

\section{The Influence of Processing Methods on Antioxidant Activity and Characteristics of Matoa Leaf Herbal Tea (Pometia pinnata)}

\author{
Putu Liana Dewi ${ }^{1}$. N.L.A. Yusasrini ${ }^{1^{*}}$, Ni Wayan Wisaniyasa ${ }^{1}$ \\ Program Studi Teknologi Pangan, Fakultas Teknologi Pertanian, \\ Universitas Udayana, Kampus Bukit Jimbaran, Badung-Bali \\ Penulis korespondensi: N.L.Ari Yusasrini, Email: ariyusasrini@unud.ac.id
}

\begin{abstract}
This study aims to determine the effect of processing methods on antioxidant activity and characteristics of matoa leaf herbal tea (Pometia pinnata) as well as to obtain the right processing method which produces matoa leaf herbal tea (Pometia pinnata) with the antioxidant activity and the best characteristics. The design used in this study was a Completely Randomized Design with the treatment of method processing consisting of 4 levels, method A (oven drying), method B (steaming and oven drying), method $\mathrm{C}$ (withening and roasting), and method D (steaming and roasting). This study was repeated 4 times to obtain 16 trial units. The data obtained were analyzed by analysis of variance and if the treatment had a significant effect it was followed by Duncan's test. The results showed that the processing method significantly affected the water content, crude fiber content, extract content in water, total flavonoids, total phenols, antioxidant activity, $\mathrm{IC}_{50}$, the sensory characteristics include color, aroma, taste and overall acceptance, and color objectively, but the treatment method has no significant effect on the ash content. The matoa leaf herbal tea with method A (oven drying) had the highest antioxidant activity and the best sensory characteristics with a water content of $8.46 \%$, ash content of $4.64 \%$, crude fiber content of $53.17 \%$, extract content in water $5.25 \%$, total flavonoids $0.87 \mathrm{mgQE} / \mathrm{g}$, total phenols $17.35 \mathrm{mgGAE} / \mathrm{g}$, antioxidant activity $87.50 \%, \mathrm{IC}_{50} 57.94 \mathrm{ppm}$ and color determination $l, a, b$ (18.33: 12.02: 10.48) as well as yellowish color sensory characteristics, very typical aroma of matoa leaf herbal tea, taste rather bitter, and overall acceptance likes.
\end{abstract}

Keywords: processing methods, antioxidant, matoa leaf, herb tea

\section{PENDAHULUAN}

Teh herbal adalah produk minuman tanaman herbal yang mempunyai khasiat untuk membantu penyembuhan suatu penyakit atau sebagai minuman herbal yang baik untuk tubuh (Hambali, 2005). Salah satu tanaman yang dapat digunakan sebagai teh herbal yaitu matoa (Pometia pinnata). Matoa dapat diolah menjadi produk yaitu teh herbal karena mengandung senyawa polifenol berupa flavonoid, saponin dan tannin (Variany. 1999). Bagian dari matoa yang dapat digunakan sebagai teh herbal yaitu daunnya.

Pembuatan teh daun matoa secara tradisonal dapat dilakukan dengan cara merebus, mengukus dan menjemur dalam waktu yang lama. Hal ini dapat menyebabkan daun matoa berubah warna menjadi coklat. Perubahan warna dari hijau menjadi coklat menandakan telah terjadinya oksidasi katekin di dalam daun (Felicia et 
al., 2016). Senyawa polifenol akan mengalami kerusakan yang diakibatkan oleh proses oksidasi enzimatis. Pengolahan teh herbal mengacu pada proses pengolahan teh tanpa fermentasi yang bertujuan untuk menjaga senyawa polifenol dan karakteristik lainnya. Pengolahan teh tanpa proses oksidasi enzimatis lebih mampu mempertahankan senyawa yang bersifat antioksidan (Winarsi, 2007). Salah satu metode tanpa oksidasi enzimatis meliputi pengeringan oven, pengukusan dan pengeringan oven, pelayuan dan penyangraian, dan pengukusan dan penyangraian.

Selama ini belum terdapat penelitian yang dilakukan untuk membandingkan keempat metode tersebut mengenai aktivitas antioksidan dan karakteristik teh herbal daun matoa. Oleh karena itu, dalam penelitian ini bertujuan untuk mengetahui pengaruh metode pengolahan terhadap aktivitas antioksidan dan karakteristik teh herbal daun matoa (Pometia pinnata) serta untuk mendapatkan metode pengolahan yang tepat yang menghasilkan teh herbal daun matoa (Pometia pinnata) yang memiliki aktivitas antioksidan dan karakteristik terbaik.

\section{METODE PENELITIAN}

\section{Bahan dan Alat}

Bahan yang digunakan dalam penelitian adalah daun matoa berwarna hijau muda (diambil 3 tangkai dari pucuk daun matoa) yang diperoleh dari (Desa
Gunaksa, Kecamatan Dawan, Kabupaten Klungkung, Bali), akuades, etanol, alkohol, DPPH (2,2-diphenyl-l-picrylhidrazyl) (Himedia), $\quad \mathrm{NaNO}_{2}$ (MERCK), $\quad \mathrm{H}_{2} \mathrm{SO}_{4}$ (MERCK), $\quad \mathrm{AICI}_{3} \quad$ (MERCK), $\mathrm{NaOH}$ (MERCK), standar kuersetin (SigmaAldrich), Folin-ciocalteu (MERCK), $\mathrm{NaCO}_{3}$ (MERCK), dan standar asam galat (Sigma-Aldrich).

Alat yang digunakan dalam penelitian adalah kompor, 32 mesh (Retsch), wajan, blender (Vienta), vortex (Maxi Mix II Type 367000), sentrifius (Danamon IEC), spektrofotometer (Genesys 10S UV -Vis), sonikator (Elma S450 H), waterbath (J.P. Selecta, s,a.), oven (Labo Do 225), timbangan analitik (Shimadzu ATY224), color reade (AccuProbe HH06), kertas Whatman No. 42, dan aluminium foil (Klin Pack).

\section{Pelaksanaan Penelitian}

Pelaksanaan penelitian meliputi beberapa tahapan yaitu sebagai berikut:

\section{Metode A (Pengeringan Oven)}

Pengolahan teh herbal daun matoa dilakukan sesuai dengan yang dikerjakan oleh Rohdiana (2007) yang dimodifikasi. Sebanyak 200 gram daun matoa yang telah disortasi, dibersihkan, dan dipisahkan antara batang dan tulang daun, selanjutnya didiamkan selama 15 menit pada suhu ruang $27{ }^{\circ} \mathrm{C}$, dikeringkan menggunakan oven pada suhu $100^{\circ} \mathrm{C}$ selama 30 menit dengan dibolak balikkan agar daun kering secara merata. Setelah daun matoa kering 
lalu didinginkan selama 5 menit, selanjutnya dilakukan penggilingan menggunakan blender dan diayak menggunakan ayakan 32 mesh.

\section{Metode B (Pengukusan dan Pengeringan Oven)}

Pengolahan teh herbal daun matoa dilakukan sesuai dengan yang dikerjakan oleh (Topuz et al., 2014) yang dimodifikasi. Sebanyak 200 gram daun matoa yang telah disortasi, dibersihkan, dan dipisahkan antara batang dan tulang daunnya lalu dikukus dengan suhu $100^{\circ} \mathrm{C}$ selama 90 detik. Daun didinginkan selama 5 menit pada suhu ruang $27{ }^{\circ} \mathrm{C}$, lalu dikeringkan dalam oven dengan suhu $100^{\circ} \mathrm{C}$ selama 30 menit, kemudian didinginkan selama 5 menit lalu daun digiling menggunakan blender dan diayak menggunakan ayakan 32 mesh.

\section{Metode C (Pelayuan dan Penyanggraia)}

Pembuatan teh herbal daun matoa dilakukan sesuai dengan yang dikerjakan oleh Setyamidjaja (2000) yang dimodifikasi. Sebanyak 200 gram daun matoa yang telah disortasi, dibersihkan, dan dipisahkan antara batang dan tulang daun. Kemudian dilayukan selama 24 jam dengan cara diangin-anginkan pada suhu ruang $27^{\circ} \mathrm{C}$. Lalu daun matoa diletakkan di atas wajan dan disangrai selama 30 menit dengan suhu $100^{\circ} \mathrm{C}$ sambil terus dibolakbalikan daunnya agar terkena panas secara merata, kemudian didinginkan selama 5 menit selanjutnya daun digiling menggunakan blender dan diayak menggunakan ayakan 32 mesh.

\section{Metode D (Pengukusan dan Penyangraian)}

Pembuatan teh herbal daun matoa dilakukan sesuai dengan yang dikerjakan oleh Thai Agricultural Standard, (2009) yang dimodifikasi. Sebanyak 200 gram daun matoa yang telah disortasi, dibersihkan, dan dipisahkan antara batang dan tulang daun. Selanjutnya dikukus dengan suhu $100^{\circ} \mathrm{C}$ selama 90 detik, kemudian didinginkan selama 5 menit. Lalu disangrai dengan suhu $100^{\circ} \mathrm{C}$ selama 30 menit, selanjutnya didinginkan selama 5 menit lalu daun digiling menggunakan blender dan diayak menggunakan ayakan 32 mesh.

\section{HASIL DAN PEMBAHASAN}

Nilai rata-rata kadar air, kadar abu, kadar serat kasar, kadar ekstrak dalam air teh herbal daun matoa dapat dilihat pada Tabel 1. Sedangkan nilai rata-rata total flavonoid, total fenol, aktivitas antioksidan dan $\mathrm{IC}_{50}$ dari teh herbal daun matoa dapat dilihat pada Tabel 2.

\section{Kadar air}

Hasil analisis ragam menunjukkan bahwa metode pengolahan berpengaruh sangat nyata $(\mathrm{P}<0,01)$ terhadap kadar air teh herbal daun matoa. Nilai rata-rata kadar air terendah diperoleh metode $\mathrm{C}$ yaitu sebesar $4,76 \%$, sedangkan nilai rata-rata kadar air tertinggi diperoleh metode B yaitu 
sebesar 12,27\%. Menurut Standar Nasional Indonesia (SNI) 3836-2013 kadar air pada produk teh kering dalam kemasan maksimal $8,0 \%$. Dengan demikian, kadar air yang dihasilkan teh herbal daun matoa pada metode C $(4,76 \%)$ dan metode D $(6,19 \%)$ sesuai dengan standar yang ditetapkan oleh Standar Nasional Indonesia (SNI). Namun metode $\mathrm{A}$ dan metode $\mathrm{B}$ belum memenuhi standar yang ditetapkan oleh Standar Nasional Indonesia (SNI).

Metode A menghasilkan kadar air lebih rendah dibandingkan dengan metode $\mathrm{B}$ dan lebih tinggi dibandingkan dengan metode $\mathrm{C}$ dan metode $\mathrm{D}$ dikarenakan tanpa mengalami proses pelayuan dan penyangraian. Pengeringan oven lebih lambat dibandingkan dengan sangrai. Hal tersebut dikarenakan proses penyangraian terjadinya proses perpindahan panas secara langsung dari wajan ke bahan.

Metode B menghasilkan kadar air paling tinggi yang disebabkan oleh proses steaming. Proses steaming diduga dapat meningkatkan kadar air bebas sehingga bahan lebih basah yang menyebabkan kadar air mengalami peningkatan.

Metode $\mathrm{C}$ menghasilkan kadar air paling rendah dikarenakan proses pelayuan yang dapat mengurangi sebagian air dalam bahan (Kusumaningrum et al., 2013) dan dapat menurunkan kadar air hingga 55-70\% (Arpah, 1993). Selain itu, pengeringan secara sangrai juga dapat menurunkan kadar air secara cepat. Laju pemanasan yang dilakukan secara cepat menyebabkan kadar air mengalami penurunan.

Kadar air metode D lebih tinggi dibandingkan metode $\mathrm{C}$ dikarenakan telah mengalami proses pengukusan sehingga kadar air bebas mengalami peningkatan. Pengeringan yang dilakukan yaitu secara sangrai dapat mempercepat laju pengeringan dibandingkan dengan oven. Hal ini sejalan dengan Nugroho et al. (2009) melaporkan bahwa selama proses penyangraian terjadinya proses perpindahan panas secara langsung dari wajan ke bahan dan perpindahan massa air dari bahan ke udara.

Tabel 1. Nilai rata-rata kadar air, kadar abu, kadar serat kasar dan kadar ekstrak dalam air teh herbal daun matoa

\begin{tabular}{ccccc}
\hline Perlakuan & $\begin{array}{c}\text { Kadar Air } \\
(\% \mathrm{~b} / \mathrm{b})\end{array}$ & $\begin{array}{c}\text { Kadar Abu } \\
(\% \mathrm{~b} / \mathrm{b})\end{array}$ & $\begin{array}{c}\text { Kadar Serat Kasar } \\
(\% \mathrm{~b} / \mathrm{b})\end{array}$ & $\begin{array}{c}\text { Kadar Ekstrak } \\
\text { dalam Air }(\% \mathrm{~b} / \mathrm{b})\end{array}$ \\
\hline Metode A & $8,46 \pm 0,44 \mathrm{c}$ & $4,64 \pm 0,09 \mathrm{a}$ & $53,17 \pm 1,05 \mathrm{~b}$ & $5,25 \pm 0,24 \mathrm{~b}$ \\
Metode B & $12,27 \pm 0,48 \mathrm{~d}$ & $4,59 \pm 0,09 \mathrm{a}$ & $45,37 \pm 1,07 \mathrm{a}$ & $3,97 \pm 0,15 \mathrm{a}$ \\
Metode C & $4,76 \pm 0,24 \mathrm{a}$ & $4,66 \pm 0,10 \mathrm{a}$ & $72,48 \pm 0,96 \mathrm{~d}$ & $11,01 \pm 0,20 \mathrm{~d}$ \\
Metode D & $6,19 \pm 0,29 \mathrm{~b}$ & $4,58 \pm 0,10 \mathrm{a}$ & $62,69 \pm 1,10 \mathrm{c}$ & $8,05 \pm 0,40 \mathrm{c}$ \\
\hline
\end{tabular}

Keterangan : huruf yang berbeda di belakang nilai rata-rata pada setiap kolom yang sama menunjukkan perbedaan yang sangat nyata $(\mathrm{P}<0.01)$. 
Tabel 2. Nilai rata-rata total flavonoid, total fenol, aktivitas antioksidan dan $\mathrm{IC}_{50}$ dari teh herbal daun matoa

\begin{tabular}{ccccc}
\hline Perlakuan & $\begin{array}{c}\text { Total Flavonoid } \\
(\mathrm{mgQE} / \mathrm{g})\end{array}$ & $\begin{array}{c}\text { Total Fenol } \\
(\mathrm{mgGAE} / \mathrm{g})\end{array}$ & $\begin{array}{c}\text { Aktivitas } \\
\text { Antioksidan }(\%)\end{array}$ & $\mathrm{IC}_{50}(\mathrm{ppm})$ \\
\hline Metode A & $0,87 \pm 0,05 \mathrm{~d}$ & $17,35 \pm 0,49 \mathrm{~d}$ & $87,50 \pm 0,78 \mathrm{~d}$ & $57,94 \pm 0,98 \mathrm{~d}$ \\
Metode B & $0,74 \pm 0,04 \mathrm{c}$ & $15,44 \pm 0,44 \mathrm{c}$ & $77,24 \pm 1,89 \mathrm{c}$ & $64,86 \pm 1,44 \mathrm{c}$ \\
Metode C & $0,52 \pm 0,06 \mathrm{a}$ & $10,94 \pm 0,39 \mathrm{a}$ & $67,13 \pm 0,76 \mathrm{a}$ & $79,93 \pm 1,89 \mathrm{a}$ \\
Metode D & $0,64 \pm 0,06 \mathrm{~b}$ & $13,99 \pm 0,65 \mathrm{~b}$ & $72,81 \pm 1,77 \mathrm{~b}$ & $73,41 \pm 0,36 \mathrm{~b}$ \\
\hline
\end{tabular}

Keterangan : huruf yang berbeda di belakang nilai rata-rata pada setiap kolom yang sama menunjukkan perbedaan yang sangat nyata $(\mathrm{P}<0.01)$.

\section{Kadar Abu}

Hasil analisis ragam menunjukkan bahwa metode pengolahan tidak berpengaruh nyata $(\mathrm{P}>0,05)$ terhadap kadar abu teh herbal daun matoa. Hal tersebut dikarenakan metode pengolahan yang digunakan tidak dapat menguapkan komponen mineral teh herbal daun matoa, sehingga kandungan mineralnya tidak jauh berbeda disetiap perlakuan. Berdasarkan Standar Nasional Indonesia (SNI) 38362013, nilai kadar abu untuk teh herbal dalam kemasan maksimal 8,0\%. Pada penelitian ini kadar abu teh herbal daun matoa dari semua perlakuan berkisar antara 4,58\% sampai 4,66\%. Hal ini menunjukkan bahwa nilai kadar abu teh herbal daun matoa memenuhi persyaratan yang ditetapkan oleh Standar Nasional Indonesia (SNI).

\section{Kadar Serat Kasar}

Hasil analisis ragam menunjukkan bahwa metode pengolahan berpengaruh sangat nyata $(\mathrm{P}<0,01)$ terhadap kadar serat kasar teh herbal daun matoa. Nilai rata-rata kadar serat kasar terendah diperoleh pada metode B yaitu sebesar $45,37 \%$, sedangkan nilai rata-rata tertinggi diperoleh metode $\mathrm{C}$ yaitu sebesar 72,48\%. Berdasarkan Standar Nasional Indonesia (SNI) kadar serat kasar yang terdapat dalam teh kering dalam kemasan maksimal 16,5\%. Teh herbal daun matoa belum memenuhi Standar Nasional Indonesi (SNI) teh kering dalam kemasan. Hal ini diduga oleh teh herbal daun matoa memiliki kadar serat kasar seperti senyawa selulosa, hemiselulosa dan lignin yang tinggi.

Metode A dalam penelitian ini menghasilkan kadar serat kasar lebih rendah dibandingkan dengan metode $\mathrm{C}$ dan metode $\mathrm{D}$ namun lebih tinggi dibandingkan dengan metode $\mathrm{B}$ dikarenakan tingkat kekeringan bahan yang berbeda-beda. Hal ini sesuai dengan penelitian yang dilakukan oleh Kusuma et al., 2019 bahwa serat kasar semakin tinggi seiring dengan meningkatnya suhu pengeringan serta suhu pengeringan yang tinggi menghasilkan kadar air yang rendah yang menghasilkan karbohidrat meningkat. 
Metode B menghasilkan kadar serat kasar paling rendah dikarenakan proses pengukusan yang menyebabkan kadar air meningkat. Menurut (Lestari et al., 2018) bahwa berkurangnya kadar air dalam bahan mengakibatkan nilai kadar serat kasar yang dihasilkan pada bahan akan semakin meningkat.

Metode $\mathrm{C}$ menghasilkan kadar serat kasar paling tinggi. Hal tersebut diakibatkan oleh proses pelayuan dan penyangraian yang menyebabkan kadar air menurun. Selain itu, suhu pengeringan secara sangrai lebih cepat dibandingkan dengan oven karena bahan bersentuhan dengan uap panas sehingga dapat mempercepat laju pengeringan. Hal ini sesuai dengan penelitian Simanjuntak (2013) bahwa semakin berkurangnya air menyebabkan kandungan serat kasar mengalami peningkatan seiring dengan meningkatnya kandungan karbohidrat.

Metode D menghasilkan kadar serat kasar lebih tinggi dibandingkan dengan metode A dan metode B dikarenakan poses pengukusan yang menimbulkan kadar air bebas mengalami peningkatan. Meningkatnnya kadar serat kasar disebabkan oleh berkurangnya kadar air dalam bahan sehingga kandungan senyawa lain seperti lemak, protein dan karbohidrat akan meningkat (Dewi et al., 2016).

\section{Kadar Ekstrak Dalam Air}

Hasil analisis ragam menunjukkan bahwa metode pengolahan berpengaruh sangat nyata $(\mathrm{P}<0,01)$ terhadap kadar ekstrak dalam air teh herbal daun matoa. Nilai rata-rata kadar ekstrak dalam air terendah diperoleh pada metode B yaitu sebesar 3,97\%, sedangkan nilai rata-rata tertinggi diperoleh metode $\mathrm{C}$ yaitu sebesar 11,01\%. Berdasarkan Standar Nasional Indonesia (SNI) kadar ekstrak dalam air yang terdapat dalam teh kering dalam kemasan minimal 32\%. Kadar ekstrak dalam air dalam penelitian ini berkisar antara $3,97 \%$ sampai $11,01 \%$. Teh herbal daun matoa belum memenuhi Standar Nasional Indonesia (SNI) teh kering dalam kemasan.

Metode A menghasilkan kadar ekstrak dalam air lebih tinggi dibandingkan dengan metode $\mathrm{C}$ dan metode $\mathrm{D}$. Menurunnya kadar ekstrak dalam air seiring dengan meningkatnya kadar air. Hal ini sesuai dengan Kusuma et al. (2017) semakin kering bahan maka ekstrak dalam air semakin meningkat sedangkan semakin basah bahan maka kadar ekstrak dalam air semakin menurun.

Metode B menghasilkan kadar ekstrak dalam air paling rendah dibandingkan dengan metode yang lain dikarenakan proses steaming dan pengeringan. Steaming diduga dapat meningkatkan kadar air bebas dalam bahan sehingga air tidak mudah mengalami 
penyerapan. Pengeringan oven lebih tinggi kadar airnya dibandingkan sangrai dikarenakan bahan bersentuhan langsung sehingga suhu yang diterima juga semakin meningkat.

Metode C menghasilkan kadar ekstrak dalam air paling tinggi. Pengeringan secara sanggai dengan menggunakan suhu tinggi menghasilkan kadar air yang rendah yang mengakibatkan bubuk menjadi lebih higroskopis dan mudah menyerap air sehingga kelarutan bubuk dalam air juga semakin besar (Purnomo, 2016).

Metode D menghasilkan kadar ekstrak dalam air lebih tinggi dibandingkan dengan metode $\mathrm{A}$ dan metode $\mathrm{B}$ namun lebih rendah dibandingkan metode $\mathrm{C}$. Pengukusan menyebabkan kadar air mengalami peningkatan. Semakin basah bahan maka sulit untuk dikeringkan dan suhu udara mengalami penurunan. Selain itu, suhu beroperasi lebih tinggi sehingga ada kemungkinan senyawa volatil mengalami penguapan yang diakibatkan oleh adanya aliran gas panas yang dapat mempengaruhi kadar ekstrak dalam air yang nantinya juga berpengaruh terhadap senyawa polifenol yang dihasilkan.

\section{Total Flavonoid}

Hasil analisis ragam menunjukkan bahwa metode pengolahan berpengaruh sangat nyata $(\mathrm{P}<0,01) \quad$ terhadap total flavonoid teh herbal daun matoa. Nilai ratarata total flavonoid tertinggi terdapat pada metode A yaitu sebesar $0,87 \mathrm{mgQE} / \mathrm{g}$, sedangkan nilai rata-rata terendah terdapat pada metode $\mathrm{C}$ yaitu sebesar $0,52 \mathrm{mgQE} / \mathrm{g}$.

Pengolahan dengan metode A menghasilkan total flavonoid paling tinggi. Hal tersebut diduga karena dalam metode ini tanpa mengalami proses pendahuluan seperti steam ataupun pelayuan. Akibat tidak adanya proses pendahuluan menyebabkan kandungan flavonoid teh hebal daun matoda tidak mengalami penurunan.

Metode B menghasilkan total flavonoid yang cenderung mengalami penurunan setelah dilakukan pengukusan. Proses pengukusan melibatkan uap panas yang menyebabkan daun matoa mengalami perubahan kimia. Menurut Jeong et al. (2004) perlakuan pemanasan pada bahan dapat menyebabkan keluarnya beberapa senyawa fenolik dengan berat molekul rendah, yang mana flavonoid yang terdapat pada teh merupakan senyawa fenolik yang memiliki berat molekul rendah.

Metode C menghasilkan total flavonoid paling rendah dikarena proses pelayuan dan pengeringan secara sangrai. Semakin lama pelayuan diduga dapat menguapkan sebagian senyawa flavonoid. Selain itu, pengeringan secara sangrai dapat menyebabkan senyawa flavonoid mengalami penurunan secara drastis. Sifat dari flavonoid yang tidak tahan panas menyebabkan sebagian senyawa flavonoid mengalami penguapan (Lenny. 2006). 
Total flavonoid metode D cenderung mengalami penurunan setelah dilakukan proses pengukusan sebelum pengeringan. Daun yang di steam menyebabkan kadar air bahan meningkat dan jika dipanaskan secara paksa senyawa bioaktif mengalami penurunan secara cepat. Flavonoid sangat sensitif terhadap panas karena senyawa yang terdapat dalam kelompok hidroksil, keton dan ikatan ganda tak jenuh mengalami oksidasi (Qiao et al., 2014).

\section{Total Fenol}

Hasil analisis ragam menunjukkan bahwa metode pengolahan berpengaruh sangat nyata $(\mathrm{P}<0,01)$ terhadap total fenol teh herbal daun matoa. Nilai rata-rata total fenol tertinggi diperoleh dari perlakuan metode A yaitu sebesar 17,35 mgGAE/g, sedangkan nilai rata-rata terendah diperoleh pada metode C yaitu sebesar 10,94 $\mathrm{mgGAE} / \mathrm{g}$.

Metode pengolahan yang berbeda menghasilkan total fenol yang berbeda pula. Pengolahan metode A menghasilkan total fenol paling tinggi dikarenakan tanpa mengalami proses pendahuluan. Proses pelayuan dan steaming dalam jangka waktu yang lama diduga dapat menguapkan senyawa fenolik. Hal ini sejalan dengan yang dikemukakan oleh (Permata, 2015) bahwa pelayuan dan pengeringan dengan jangka waktu yang panjang dapat merusak senyawa fenolik karena senyawa tersebut tidak tahan terhadap panas.
Total fenol yang dihasilkan metode B mengalami penurunan diduga karena proses pengukusan dengan suhu $100^{\circ} \mathrm{C}$ dan juga proses pengeringan pada suhu $100^{\circ} \mathrm{C}$ sehingga proses pemanasan yang berulang ini menyebabkan penurunan senyawa fenolik lebih banyak. Proses steam menyebabkan terjadinya kerusakan dinding sel dalam daun.

Metode $\mathrm{C}$ menghasilkan total fenol paling rendah. Proses pelayuan yang dilakukan selama 24 jam menyebabkan teh herbal daun matoa mengalami oksidasi. Pengeringan secara sangrai juga diduga dapat menurunkan senyawa fenolik secara cepat dikarenakan bahan bersentuhan langsung dengan uap panas. Hal ini sejalan dengan pendapat (Rohdiana, 2001) bahwa proses pengeringan mengakibatkan senyawa yang termasuk antioksidan mengalami kerusakan yang dipengaruhi oleh reaksi oksidasi enzimatis sehingga kualitas bahan pangan mengalami penurunan.

Metode D menghasilkan total fenol lebih tinggi dibandingkan dengan metode $\mathrm{C}$ dan lebih rendah dibandingkan dengan metode A dan metode B disebabkan oleh proses pengolahan tanpa mengalami pendahuluan seperti pelayuan akan tetapi mengalami proses pengukusan/steaming. Selain itu, pengeringan yang dilakukan dengan menggunakan wajan menyebabkan teh herbal daun matoa secara cepat mengalami reaksi oksidasi. 


\section{Aktivitas Antioksidan dan $\mathbf{I C}_{\mathbf{5 0}}$}

Hasil analisis ragam menunjukkan bahwa metode pengolahan berpengaruh sangat nyata $(\mathrm{P}<0,01)$ terhadap aktivitas antioksidan teh herbal daun matoa. Nilai rata-rata aktivitas antioksidan tertinggi diperoleh pada perlakuan metode A yaitu sebesar $87,50 \%$ sedangkan nilai rata-rata terendah diperoleh pada perlakuan metode $\mathrm{C}$ yaitu sebesar $67,13 \%$.

Metode A menghasilkan aktivitas antioksidan paling tinggi. Hal tersebut dikarenakan selama pengolahan tidak adanya proses pendahuluan yang menyebabkan senyawa antioksidan mengalami penguapan secara cepat. Tingginya aktivitas antioksidan teh herbal daun matoa dipengaruhi juga oleh kadar total fenol dan flavonoid karena senyawa tersebut adalah bagian dari antioksidan (Yondra et al., 2014).

Metode B menghasilkan aktivitas antioksidan yang cenderung menurun diduga proses pengukusan dan pengeringan. Steaming dapat menambah kadar air bebas, jika dilakukan pengeringan dengan suhu tinggi kemungkinan senyawa antioksidan mengalami kerusakan. Metode C menghasilkan aktivitas antioksidan paling rendah karena mengalami proses pelayuan selama 24 jam dan pengeringan secara sangrai. Menurut Kusumaningrum et al. (2013) semakin lama proses pelayuan maka aktivitas antioksidan mengalami penurunan hal tersebut diakibatkan oleh adanya perubahan kimia dan hilangnya sebagian senyawa antioksidan karena teroksidasi.

Metode D menghasilkan aktivitas antioksidan yang lebih rendah dibandingkan dengan metode A dan metode B namun lebih tinggi dibandingkan dengan metode $\mathrm{C}$ dikarenakan proses pengukusan dan pengeringan. Proses pengukusan menyebabkan daun mengalami pelayuan namun ketika dikeringkan dengan suhu tinggi daun akan mengalami kerusakan. Hal ini dijelaskan oleh Winarno (2002) bahwa proses pengeringan dengan suhu yang tinggi dengan menggunakan penyangraian mengakibatkan rusaknya zat aktif yang terdapat pada bahan pangan. Hasil analisis ragam menunjukkan bahwa metode pengolahan berpengaruh sangat nyata $(\mathrm{P}<0,01)$ terhadap $\mathrm{IC}_{50}$ teh herbal daun matoa. Nilai rata-rata $\mathrm{IC}_{50}$ terendah diperoleh pada perlakuan metode A yaitu sebesar 57,94ppm, sedangkan nilai rata-rata tertinggi diperoleh dari perlakuan metode $\mathrm{C}$ yaitu sebesar 79,93ppm. Pengolahan teh herbal daun matoa dengan metode A menghasilkan $\mathrm{IC}_{50}$ paling rendah, sedangkan perlakuan metode $\mathrm{C}$ menghasilkan $\mathrm{IC}_{50}$ paling tinggi dikarenakan terjadinya proses oksidasi enzimatis. Semakin kecil nilai IC $_{50}$ maka kemampuan aktivitas antioksidan lebih tinggi dalam menangkal radikal bebas. Teh herbal daun matoa dikategorikan dalam antioksidan kuat pada perlakuan metode A (pengeringan oven). 
Tabel 3. Rata-rata nilai warna teh herbal daun matoa

\begin{tabular}{cccccc}
\hline \multirow{2}{*}{ Perlakuan } & \multicolumn{4}{c}{ Rata-rata perlakuan } \\
& Metode A & Metode B & Metode C & Metode D \\
\hline \multirow{2}{*}{ Warna } & $l$ & $18,33 \mathrm{a}$ & $18,39 \mathrm{a}$ & $16,66 \mathrm{~b}$ & $16,20 \mathrm{~b}$ \\
& $a$ & $12,02 \mathrm{~b}$ & $11,11 \mathrm{~b}$ & $13,43 \mathrm{a}$ & $11,48 \mathrm{~b}$ \\
& $b$ & $10,48 \mathrm{~b}$ & $12,31 \mathrm{a}$ & $8,76 \mathrm{c}$ & $9,46 \mathrm{bc}$ \\
\hline
\end{tabular}

Keterangan : huruf yang berbeda dibelakang nilai rata-rata menunjukkan perbedaan yang nyata pada setiap kolom $(\mathrm{P}<0,01)$.

\section{Penentuan Warna}

Hasil analisis ragam menunjukkan bahwa metode pengolahan berpengaruh nyata $(\mathrm{P}>0,01)$ terhadap warna air seduhan teh herbal daun matoa. Nilai rata-rata warna dapat dilihat pada Tabel 3.

Pada Tabel 3. dapat dilihat bahwa metode B menghasilkan tingkat kecerahan paling tinggi $(l, a, b=18,39 ; 11,11 ; 12,31)$ dan metode $\mathrm{D}$ menghasilkan tingkat kecerahan paling rendah $(l, a, b=16,20$; 11,48; 9,46). Semakin tinggi nilai $l$ maka warna yang dihasilkan semakin cerah, sedangkan semakin rendah nilai $l$ maka warna yang dihasilkan semakin gelap (Kusumaningrum et al., 2013). Semakin tinggi nilai a maka warna semakin merah, namun semakin rendah sampel warna akan semakin hijau. Nilai $b$ menunjukkan bahwa semakin tinggi nilai $b$ maka warna semakin kuning, semakin rendah nilai $b$ maka warna semakin biru (Suyanto, 2017).

\section{Karakteristik Sensori}

Karakteristik sensori teh herbal daun matoa dianalisis menggunakan uji Friedman terhadap warna, aroma, dan rasa serta uji hedonik terhadap penerimaan keseluruhan. Nilai rata-rata warna, aroma dan rasa serta uji hedonik terhadap penerimaan keseluruhan dapat dilihat pada Tabel 4.

Tabel 4. Nilai rata-rata karakteristik sensori air seduhan teh herbal daun matoa

\begin{tabular}{cccccc}
\hline \multirow{2}{*}{ Perlakuan } & \multicolumn{4}{c}{ Rata-rata perlakuan } \\
& Metode A & Metode B & Metode C & Metode D \\
\hline Warna* & Rangking & $1,30 \mathrm{a}$ & $1,92 \mathrm{~b}$ & $3,52 \mathrm{~cd}$ & $3,26 \mathrm{~cd}$ \\
Aroma** & Rangking & $1,30 \mathrm{a}$ & $2,40 \mathrm{~b}$ & $2,68 \mathrm{c}$ & $3,62 \mathrm{~d}$ \\
Rasa*** & Rangking & $2,96 \mathrm{~d}$ & $3,72 \mathrm{c}$ & $1,36 \mathrm{a}$ & $1,96 \mathrm{~b}$ \\
Penerimaan & Hedonik & $3,68 \mathrm{a}$ & $2,86 \mathrm{a}$ & $1,30 \mathrm{~b}$ & $2,16 \mathrm{ac}$ \\
Keseluruhan**** & & & &
\end{tabular}

Keterangan: huruf yang berbeda dibelakang nilai rata-rata menunjukkan perbedaan yang nyata pada setiap kolom $(\mathrm{P}<0,01)$. 


\section{Warna}

Hasil uji Friedman menunjukkan bahwa metode pengolahan berpengaruh nyata $(\mathrm{P}>0,01)$ terhadap warna air seduhan teh herbal daun matoa. Berdasarkan nilai rata-rata warna yaitu 1,30 (kekuningan) hingga 3,52 (merah kekuningan). Warna yang dihasilkan setiap perlakuan dari metoda A, B, C dan D berturut-turut yaitu kekuningan, kuning kehijauan, merah kekuningan, dan kuning kecoklatan. Warna yang dihasilkan tergantung bagaimana proses pengolahan yang dilakukan seperti pelayuan, steaming dan pengeringan. Semakin lama pelayuan warna yang dihasilkan semakin pudar dikarenakan daun mengalami oksidasi. Proses steaming menyebabkan warna lebih cerah.

\section{Aroma}

Hasil uji Friedman menunjukkan bahwa metode pengolahan berpengaruh sangat nyata $(\mathrm{P}<0,01)$ terhadap aroma air seduhan teh herbal daun matoa. Berdasarkan nilai rata-rata aroma yaitu 1,30 (sangat khas teh herbal daun matoa) hingga 3,62 (tidak khas teh herbal daun matoa). Aroma yang dihasilkan untuk setiap perlakuan berbeda-beda. Aroma yang sangat khas teh herbal daun matoa terdapat pada metode A dan tidak khas teh herbal daun matoa terdapat pada metode D. Aroma mengalami penurunan ataupun peningkatan tergantung dari bagaimana proses pengolahan yang dilakukan.

\section{Rasa}

Hasil uji Friedman menunjukkan bahwa metode pengolahan berpengaruh sangat nyata $(\mathrm{P}<0,01)$ terhadap rasa air seduhan teh herbal daun matoa. Berdasarkan nilai rata-rata rasa yaitu 1,36 (sangat tidak pahit) hingga 3,72 (pahit). Rasa pahit dari senyawa tanin dapat mengalami peningkatan ataupun penurunan ditimbulkan karena metode pengolahan seperti proses pengukusan, pelayuan dan pengeringan.

\section{Penerimaan keseluruhan}

Hasil uji Friedman menunjukkan bahwa metode pengolahan berpengaruh nyata $\quad(\mathrm{P}>0,01)$ terhadap penerimaan keseluruhan air seduhan teh herbal daun matoa. Nilai rata-rata penerimaan keseluruhan yang diberikan oleh panelis berkisar antara 3,68 (suka) hingga 1,30 (tidak suka).

\section{KESIMPULAN DAN SARAN}

\section{Simpulan}

Berdasarkan hasil penelitian yang telah dilakukan dapat diambil kesimpulan yaitu metode pengolahan berpengaruh sangat nyata terhadap kadar air, kadar serat kasar, kadar ekstrak dalam air, total flavonoid, total fenol, aktivitas antioksidan, $\mathrm{IC}_{50}$ dan karakteristik sensori meliputi warna, aroma, rasa dan penerimaan keseluruhan. Berpengaruh nyata terhadap warna secara obyektif, namun tidak berpengaruh nyata terhadap kadar abu. 
Metode A (pengeringan oven) menghasilkan teh herbal daun matoa dengan aktivitas antioksidan dan karakteristik terbaik dengan kriteria kadar air 8,46\%, kadar abu 4,64\%, kadar serat kasar $53,17 \%$, kadar ekstrak dalam air $5,25 \%$, total flavonoid $0,87 \mathrm{mgQE} / \mathrm{g}$, total fenol 17,35mgGAE/g, aktivitas antioksidan $87,50 \%, \quad \mathrm{IC}_{50} 57,94 \mathrm{ppm}$ dan penentuan warna $l, a, b(18,33 ; 12,02 ; 10,48)$ serta karakteristik sensori warna kekuningan, aroma sangat khas teh herbal daun matoa, rasa agak pahit, dan penerimaan keseluruhan suka.

Saran

Perlu dilakukan penelitian lebih lanjut mengenai suhu dan lama pengeringan optimum terhadap pembuatan teh herbal daun matoa dengan metode $\mathrm{A}$ (pengeringan oven) agar kandungan senyawa-senyawa aktif tidak mengalami penurunan.

\section{DAFTAR PUSTAKA}

Arpah, M. 1993. Pengawasan Mutu Pangan. Tarsito. Bandung.

Darmayanti E, Kusharto, C.M, Suprihartini R, Rohdiana D. 2007. Studi kandungan katekin dan turunannya sebagai antioksidan alami seta karakteristik organoleptik produk teh murbei dan teh camellia-murbei. Media Gizi dan Keluarga. 32(1) :95-103.

Dewi, N.L.P.D.U., L.P. Wrasiati, dan D.A.A. Yuarini 2016. Pengaruh suhu dan lama penyangraian dengan oven drier terhadap karakteristik teh beras merah jatiluwih. Jurnal Rekayasa dan Manajemen Agroindustri 4 (2) : 1-12.

Hambali, E.M.Z. Nasution dan E. Herliana. 2005. Membuat Aneka Herbal Tea. Penerbit: Swadaya, Jakarta.
Felicia, N., I.W.R. Widarta, dan N.L.A. yusasrini. 2016. Pengaruh ketuaan daun dan metode pengolahan terhadap aktivitas antioksidan dan karakteristik sensoris teh herbal bubuk daun alpukat (Persea americana Mill.). Jurnal ITEPA, 5(2), 85-94.

Jeong, S. M., Kim, S. Y., Kim, D. R., Jo, S. C., Nam, K. C., Ahn, D. U., \& Lee, S. C. 2004. Effect of heat treatment on the antioxidant activity of extracts from citrus peels. Journal of agricultural and food chemistry, 52(11), 3389- 3393

Lenny, S. 2006. Senyawa flavonoida, fenilpropanoida dan alkaloida. http://repository.usu.ac.id/bitstream/12 3456789/1842/3/06003489.pdf.txt. Diakses tanggal 5 April 2020.

Nugroho, J., J. Lumbanbatu, dan S. Rahayoe. 2009. Pengaruh suhu dan lama penyangraian terhadap sifat fisikmekanis biji kopi robusta. Makalah Bidang Teknik Produk Pertanian, Seminar Nasional dan Gelar Teknologi PERTETA, Mataram 8 - 9 Agustus 2009.

Kusuma, I. G. N. S., I. N. K. Putra., dan L. P. T. Darmayanti. 2019. Pengaruh suhu pengeringan terhadap aktivitas teh herbal kulit kakao (Theobroma cacao L.) 8(1): 85-93.

Kusumaningrum, R.,. A. Supriadi, dan S. Hanggita. 2013. Karakteristik dan mutu teh bunga lotus (Nnelumbo nucifera). Fishtech : 2(1).

Lestari, M., E. R. Muhammad dan H. Rusulu. 2018. Pengaruh umur daun pala dan jenis pengeringan terhadap sifat kimia dan organoleptik teh herbal daun pala. Jurnal Penelitian: 07(02).

Rohdiana, D. 2007. Petunjuk Teknis Pengolahan Teh. Pusat Penelitian Teh dan Kina. Gambung.

Setyamidjaja, D. 2000. Teh: Budi Daya dan Pengolahan Pascapanen. Penerbit Kanisius: Yogyakarta.

Simanjuntak, L., S. Harun, and R. Efendi. 2014. Penerimaan panelis terhadap teh herbal dari kulit buah manggis (Garcinia Manggis L.) dengan Perlakuan Suhu Pengeringan. Jurnal 
Online Mahasiswa Fakultas Pertanian Riau.

Suyanto, A. 2017. Kuliah Warna Pangan. http://tekpan.unimus.ac.id/wpcontent/uploads/2017/10/kuliahwarna-pangan.ppt. Diakses pada tanggal 18 Oktober 2019.

Standar Nasional Indonesia (SNI) 38362013. 2013. Standar Mutu Teh Kering. Dewan Standardisasi Nasional. Jakarta.

Thai Agricultural Standard (Tas 30002009). Mulberry Tea. Ministry Of Agriculture And Cooperatives. Bangkok.

Topuz, A., C. Dincer, M. Torun, I. Tontul, H.S. Nadeem, A. Haznedar, and F. Ozdemir. 2014. Physicochemical properties of turkish green tea powder: effects of shooting period, shading,. And clone. Turkish Journal of Agriculture and Forestry 38:233-241.5.

Permata, D. 2015. Aktivitas inhibisi amilase dan total polifenol teh daun sisik naga pada suhu dan pengeringan yang berbeda. Seminar agroindustri dan lokakarya nasional FKPT-TPI, 2-3 September 2015. Universitas Andalas.

Purnomo, W., L. U. Khasanah, dan B. K. Anandito.2016. Pengaruh ratio kombinasi maltodekstrin, karagenan dan whey terhadap karakteristikmikroenkapsulan pewarna alami daun jati (Tectona grandis Lf). Jurnal Aplikasi Teknologi Pangan, 3(3).

Qiao, L, Y. Sun, R. Chen, Y. Fu, W. Zhang, X. Li, J. Chen, Y. Shen, X. Ye. 2014. Sonochemical effects on 14 flavonoids common in citrus: relation to stability. PLOS ONE 9(2):1-10.

Variany, G. 1999. Isolasi dan Identifikasi Flavonoid dari Daun Matoa (Pometia pinnata) J.R\&G.Forst, nomor 1785, Media Informasi Penelitian Herbal Fakultas Farmasi. Universitas Tanjung Pura. Pontianak.

Winarsi, H. 2007 Antioksidan Alami dan Radikal Bebas. Potensi dan Aplikasinya dalam Kesehatan. Kanisius. Yogyakarta.

Winarno, F. G. 2002. Kimia Pangan dan Gizi. Gramedia, Jakarta. 